\title{
Application of Radial Tool Movement in Electrical Discharge Machining Process for Boring Operation
}

\author{
Sudhanshu Kumar, Harshit K. Dave, and Keyur P. Desai
}

\begin{abstract}
The objective of this research work is to perform boring operation in electrical discharge machining process on AISI 304 workpiece material. Boring operation was successfully accomplished using tool actuation on radial path in electrical discharge machining process. The diameter of predrilled hole cavities were enlarged to $10 \mathrm{~mm}$ bore diameter. The boring operations were performed with three different diameter of tool electrode i.e. 7, 8 and $9 \mathrm{~mm}$ at three different orbital speed of tool electrode i.e. $0.05,0.09$ and $0.13 \mathrm{~mm} / \mathrm{s}$. The machining responses were measured in terms of material removal rate $(M R R)$, surface roughness $\left(R_{a}\right)$ and radial overcut $\left(O_{c}\right)$.
\end{abstract}

Index Terms-Boring, EDM, orbital, radial.

\section{INTRODUCTION}

Electrical discharge machining (EDM) is a process in which material is removed by the action of repetitive sparks between two conductive electrodes. The electrodes are submersed in dielectric fluid and are separated by very small gap, usually $0.01-0.5 \mathrm{~mm}$ [1]. Since EDM is non contact type of machining process, no any cutting force is involved during machining process. Therefore any conducting material irrespective of their hardness or fragileness can be easily machined. In electrical discharge machining process, millions of sparks produced at the nearest distance between tool electrode and workpiece and remove material by creating tiny craters on surfaces. Hence, the shape of tool electrode is reproduced on workpiece [2].

Generally electrical discharge machining process is used to generate identical shape of tool electrode on workpiece in die - mould industries [3]. This requires the fabrication of tool electrode identical to the shape and size of cavity to be generated. This is also known as cavity sinking or die sinking EDM process where only vertical reciprocating movement of tool electrode is given and basically used for drilling operation. However, the advantage of spark erosion of EDM process is utilized for other machining operations also like milling [4] turning [5], grinding [6] etc. by providing rotary and or reciprocating motions either to the tool electrode or workpiece.

In this study, electrical discharge machining process was used for boring operation. Boring is a process of enlarging a hole size that has already been drilled by some other means [7]. Conventionally boring process is performed on lathe or milling machine using a hard and rigid tool with appropriate inserts. However, conventional boring operation experiences

Manuscript received March 10, 2016; revised May 25, 2016.

The authors are with the Department of Mechanical Engineering at the S. V. National Institute of Technology, Surat, 395007 India (e-mail: sudhanshukumar27@gmail.com, keyur_desai@yahoo.com). vibration and deflection of boring tool that results poor surface quality as well as lower dimensional accuracy. Geometrical and rigidness requirement of boring tool makes the boring process challenging on the conventional machine. Unlike conventional boring process, EDM boring process deals with all conductive material irrespective to hardness and strength. Additionally EDM does not require harder tool than workpiece, boring operation can be achieved with any conducting material. Due to absence of cutting force and vibration during electro discharge machining, good surface finish and better dimensional accuracy can be achieved.

The present research work focused on the application of EDM process for boring process performed on AISI 304 work material. The boring of predrilled cavities was achieved using radial tool orbiting in EDM process. The bore size of 10 $\mathrm{mm}$ diameter was achieved from three different sizes of predrilled cavities i.e. $7 \mathrm{~mm}, 8 \mathrm{~mm}$ and $9 \mathrm{~mm}$ diameter. The next section describes the experimental plan and procedure.

\section{EXPERIMENTAL PLAN AND PROCEDURE}

\section{A. Radial Tool Orbiting}

Actuation of tool electrode around its vertical axis is known as tool orbiting. The concept of tool orbiting in electrical discharge machining was adopted for process improvement. Orbiting of tool electrode improves the flushing of dielectric fluid and hence increases the material removal rate. Researchers have defined the tool orbiting based on tool path movement in EDM process such as helical [8], spiral [9], cylindrical [10], slicing [10] orbiting etc. In radial tool orbiting technique, movement of tool electrode is guided on linear path. Tool electrode actuates around the centre of a circle on the locus of radius, as shown in Fig. 1(a). During machining under radial orbital condition, tool electrode first moves into the full depth of cavity, on path 1 , as defined in Fig. 1(b). Then its travel in vertical axis is stopped. After locking the movement in vertical axis, tool electrode is allowed to actuate on the path that is perpendicular to its vertical axis i.e. on along with the radius of a circle. Tool electrode moves on path 2 (as indicated in Fig. 1(b)) towards the circumference of circular cavity. With this movement of tool electrode, material is eroded from the cavity wall. The amount of material to be eroded in radial direction is defined by the tool offset from the centre of cavity. After erosion of material, tool electrode returns back to its initial position i.e. at centre of cavity. The next movement of tool electrode is guided at an angular increment of $5^{\circ}$ from previous path. Thus total 72 movement of tool electrode with an advancement of $5^{\circ}$ from preceding path creates a circular cavity with larger diameter (diameter equals to the summation of tool diameter and twice the offset distance). 


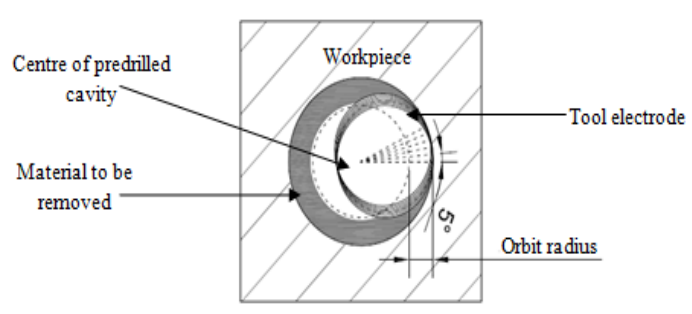

(a)

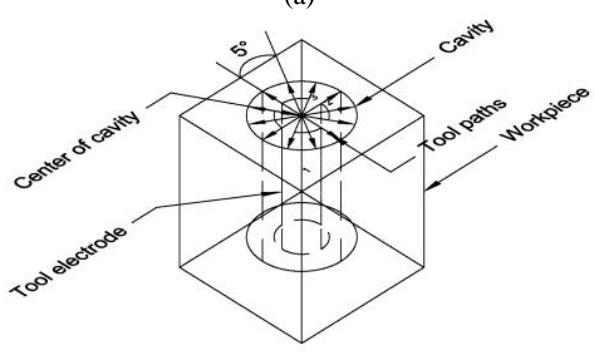

(b)

Fig. 1 (a) Top view of radial tool movement (b) Isometric view of radial tool movement in EDM.

At the end of machining, tool electrode returns back to its initial position. The travelling speed and amount of tool offset of tool electrode is electronically controlled during machining.

\section{B. Machine Tool}

Experiments were performed on JOEMARS (model-JM322) make die sinking EDM machine. Fig. 2 shows the machine setup. In this machine, the $\mathrm{Z}$ axis is servo controlled and can be programmed to follow an NC code which is fed through the control panel. The $\mathrm{X}$ and $\mathrm{Y}$ movement of table is manually controlled. The servo control feedback is based on the gap voltage between the tool and the work piece. This machine is equipped with orbit cut controller which precisely controls the two stepped motors. Stepped motors are attached with the vertical head of the die-sinking machine. These attached motors guide the tool holder according to inputted path. The maximum displacement of tool under orbiting condition is $4.999 \mathrm{~mm}$ from its centre. Thus, it can machine up-to the $9.999 \mathrm{~mm}$. The orbital cut mechanism can control $\mathrm{X}, \mathrm{Y}$ and $\mathrm{Z}$ axis movement independently with $1 \mu \mathrm{m}$ precision.

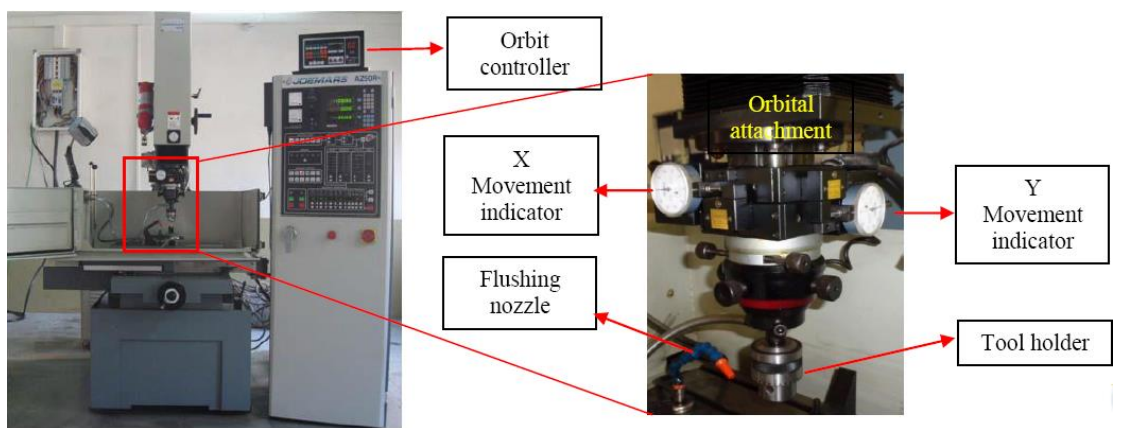

Fig. 2. Electrical discharge machine set up with orbit cut arrangement.

The movement of tool electrode during radial cut machining can be clearly observed in two dial gauge provided with the orbital attachment.

\section{Workpiece and Tool Electrode}

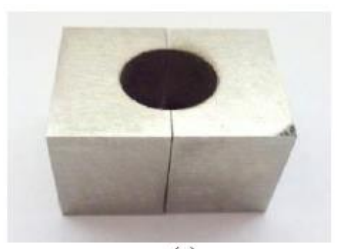

(a)

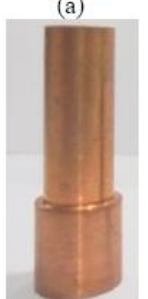

(c)

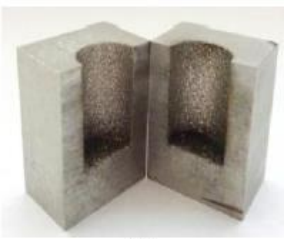

(b)

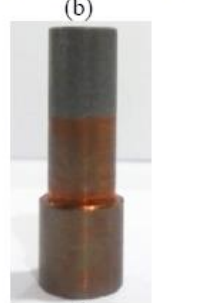

(d)
Fig. 3 (a) Workpiece with predrilled cavity (b) Cavity after boring in EDM process (c) Copper tool electrode before machining(d) Copper tool electrode after machining.

Electrolytic Copper and AISI 304 were selected as the tool electrode and workpiece material respectively. Split cross section of workpiece material was used for experimentations. The split workpiece helps better handling during surface roughness measurement. Initial cavity of $7 \mathrm{~mm}, 8 \mathrm{~mm}$ and 9 $\mathrm{mm}$ were drilled at $10 \mathrm{~mm}$ depth using die-sinking EDM process. These drilled cavities were used for boring process. The tool electrodes are prepared with three different diameters namely, 7, 8 and $9 \mathrm{~mm}$ diameter and $20 \mathrm{~mm}$ long. Fig. 3 shows the workpiece and tool electrode before and after boring operation.

\section{Machining Parameters}

In order to achieve the final cavity size of $10 \mathrm{~mm}$ diameter with $7 \mathrm{~mm}, 8 \mathrm{~mm}$ and $9 \mathrm{~mm}$ diameter tool electrode, $1.5 \mathrm{~mm}$, $1 \mathrm{~mm}$ and $0.5 \mathrm{~mm}$ tool offset or orbital radius respectively were selected. Other parameters were selected using some trial experiments as well as user manual of EDM like, Peak current 13 [A], Pulse on time 195 [ $\mu \mathrm{s}$ ], Pulse off time 85 [ $\mu \mathrm{s}$ ], Spark voltage $40[\mathrm{~V}]$, Orbital speed $0.13 \mathrm{~mm} / \mathrm{s}$, Machining time 0.667 [s] and Flushing time 0.267 [s] etc. The machining parameters are given in Table I.

TABLE I: MACHINING PARAMETERS

\begin{tabular}{lll}
\hline \hline Parameters & Unit & Values \\
\hline Peak current & $\mathrm{A}$ & 13 \\
Pulse on time & $\mu \mathrm{s}$ & 195 \\
Pulse off time & $\mu \mathrm{s}$ & 85 \\
Spark voltage & $\mathrm{V}$ & 40 \\
Orbital speed & $\mathrm{mm} / \mathrm{s}$ & 0.13 \\
Machining time & $\mathrm{s}$ & 0.667 \\
Flushing time & $\mathrm{s}$ & 0.267 \\
Orbital radius & $\mathrm{mm}$ & $1.5,1.0,0.5$ \\
\hline \hline
\end{tabular}


The performance of the boring process in EDM was measured in terms of material removal rate (MRR), and overcut $\left(\mathrm{O}_{\mathrm{c}}\right)$ and these were evaluated using equation 1 and 2 respectively.

$$
M R R=\left(\frac{W_{w b}-W_{w a}}{\rho_{w} \times t}\right)
$$

where, $W_{w b}=$ weight of work piece before machining, $W_{w a}=$ weight of work piece after machining, $\rho_{w}=$ density of AISI304 $\left(8 \mathrm{gm} / \mathrm{mm}^{3}\right), t=$ machining time.

$$
\text { Overcut }\left(O_{c}\right)=\frac{D_{a}-D_{t}}{2}
$$

where, $D_{t}=\left(2 \times S_{r}\right)+t, D_{a}=$ Actual diameter of hole, $D_{t}=$ Target diameter of hole, $S_{r}=$ Orbital radius, $t=$ Diameter of tool electrode.

Surface roughness was measured with Mitutoyo Surftest (SJ-400). Surface roughness was recorded at total six different locations on machined cavity and average of six observations was represented as the roughness of cavity.

TABLE II: EXPERIMENTAL PLAN AND THEIR RESULTS

\begin{tabular}{lllllll}
\multicolumn{7}{c}{ TABLE II: EXPERIMENTAL PLAN AND THEIR RESULTS } \\
\hline \hline Exp. No. & Orbital radius & Orbital speed & Tool diameter & MRR $(\mathrm{mm} 3 / \mathrm{min})$ & $\mathrm{Ra}(\mu \mathrm{m})$ & Overcut $(\mathrm{mm})$ \\
\hline 1 & 0.5 & 0.05 & 9 & 2.587 & 9.243 & 0.069 \\
2 & 1.0 & 0.05 & 8 & 2.419 & 9.498 & 0.069 \\
3 & 1.5 & 0.05 & 7 & 2.276 & 11.525 & 0.045 \\
4 & 0.5 & 0.09 & 9 & 3.377 & 9.504 & 0.072 \\
5 & 1.0 & 0.09 & 8 & 3.484 & 10.652 & 0.051 \\
6 & 1.5 & 0.09 & 7 & 3.396 & 10.631 & 0.055 \\
7 & 0.5 & 0.13 & 9 & 4.689 & 10.375 & 0.069 \\
8 & 1.0 & 0.13 & 8 & 4.327 & 12.186 & 0.024 \\
9 & 1.5 & 0.13 & 7 & 5.466 & 11.310 & 0.020 \\
\hline \hline
\end{tabular}

\section{RESUlT AND DisCUSSIONS}

All experiments were performed on die-sinking EDM with orbital attachment. The controller facilitates to move the tool electrode radially to generate circular cavity. Tool electrode can move up-to $4.5 \mathrm{~mm}$ of radius with 10 different speeds. First tool electrode was moved inside the drilled cavity (predrilled cavities of $10 \mathrm{~mm}$ depth) and then radial movement of tool electrode was given to erode material.

\section{A. Effect on Material Removal Rate (MRR)}

Orbital speed is the speed of tool movement during machining. Effect of orbital speed during radial movement in EDM process was found out by varying one factor at a time, other factors were kept constant. The size of cavity was fixed to $10 \mathrm{~mm}$ diameter. To achieve this diameter of cavity with 7 , 8 and $9 \mathrm{~mm}$ tool diameter, orbital radius was varied at 1.5, 1.0 and $0.5 \mathrm{~mm}$. The speed of tool electrode was varied at 0.05 , 0.09 and $0.13 \mathrm{~mm} / \mathrm{s}$. Fig. 4 shows the variation of MRR with different orbital speed at different orbital radius. From Fig. 4, it can be observed that MRR was increasing with increase in orbital speed.

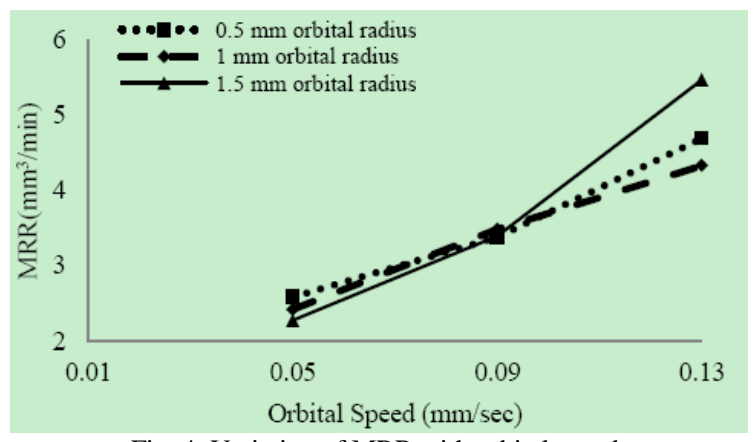

Fig. 4. Variation of MRR with orbital speed.

Minimum MRR was found with $0.05 \mathrm{~mm} / \mathrm{s}$ orbital radius and was significantly increasing with increase in orbital speed. When speed was maximum, MRR obtained was highest. Highest and lowest MRR was obtained at higher orbital radius. The increasing trend of MRR was may be due to the increase in speed of tool electrode during radial orbit machining. With increase in speed of tool movement, time consumes in travelling of tool from centre to the machined area decreases and it improves the material removal rate.

\section{B. Effect on Surface Roughness $\left(R_{a}\right)$}

Surface roughness gives the idea about the machining

parameters that have interacted with surface during machining. The surface generated by EDM process comprises of overlapped re-solidified layers, craters and micro cracks etc. Here, surface roughness was measured in terms of arithmetic average of absolute values of peaks and valleys from ideal surface and it is expressed in $R_{a}$. Effect on surface roughness $\left(R_{a}\right)$ was plotted in Fig. 5 .

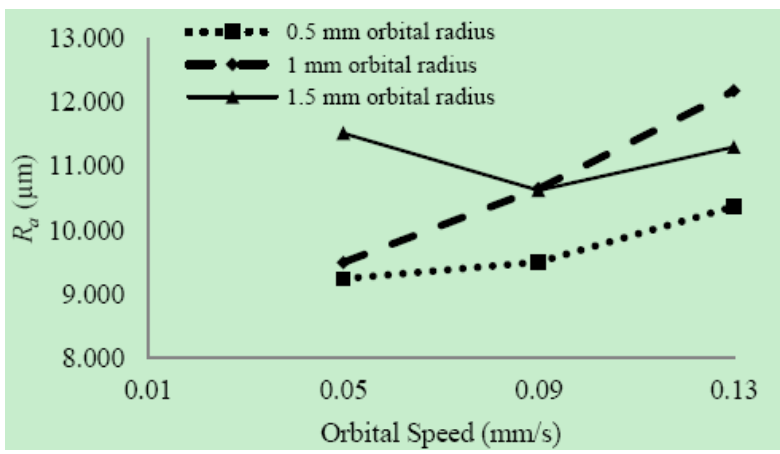

Fig. 5. Variation of $R_{a}$ with orbital speed.

It can be observed that the values of surface roughness for radius 0.5 and $1.0 \mathrm{~mm}$ are minimum at $0.05 \mathrm{~mm} / \mathrm{s}$ orbital speed. While for higher orbital radius, minimum roughness was found at $0.09 \mathrm{~mm} / \mathrm{s}$ orbital speed. At higher orbital speed, tool electrode quickly comes in contact with spark and due to frequently sparking on work surface, larger and more irregular craters form that increases the average roughness of machined cavities. For the better understanding, some micrographs of machined surface were taken and shown in 
Fig. 6.

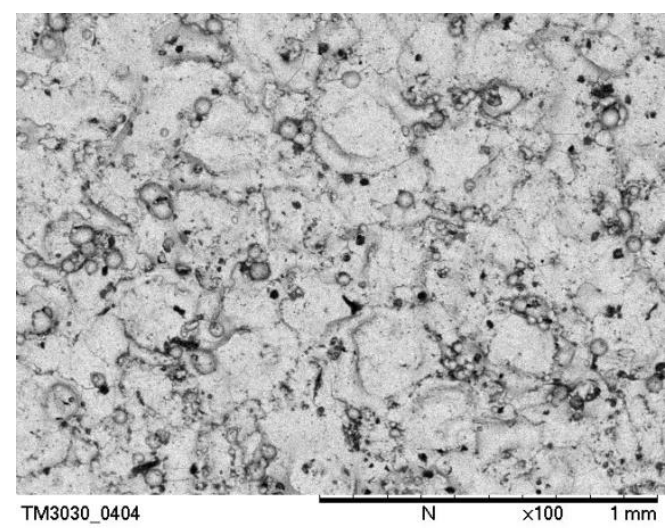

(a)

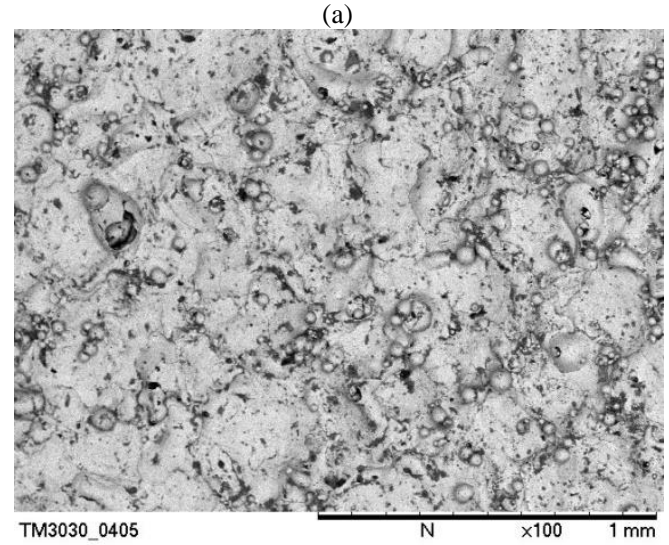

(b)

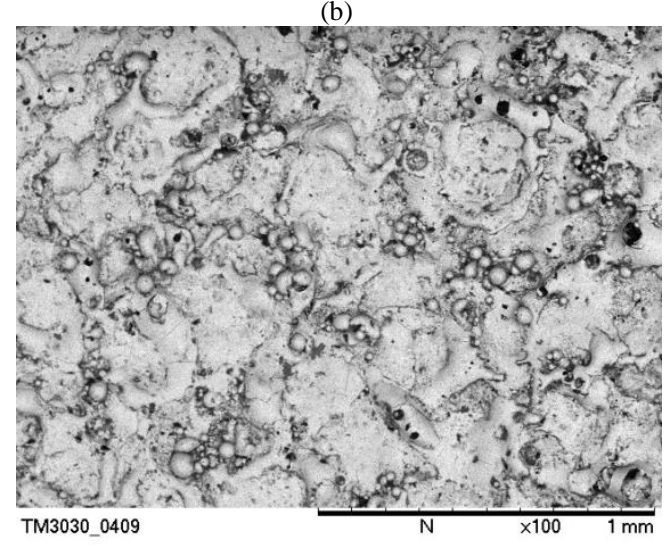

(c)

Fig. 6. Micrographs of machined surface generated with (a) $S_{r}=1.0 \mathrm{~mm}, S_{o}=$ $0.05 \mathrm{~mm} / \mathrm{s}$ (b) $S_{r}=1.0 \mathrm{~mm}, S_{o}=0.09 \mathrm{~mm} / \mathrm{s}$ (c) $S_{r}=1.0 \mathrm{~mm}, S_{o}=0.13 \mathrm{~mm} / \mathrm{s}$.

From Fig. 6, it can be observed that the randomness of the craters is more in Fig. 6(c) followed by Fig. 6(b) and Fig. 6(a). Fig. 6(a) represents the micro image of surface machined with the lowest orbital speed, the lowest orbital speed of tool electrode generates relatively smaller craters and their outer boundaries have lesser thickness. Increase in orbital speed causes increase in craters depth. Some spherical balls like structure can also be found on the surface. These sphere like structures are the re-solidified materials that have not been removed. The re-solidified structures are more visual in Fig. 6(c). This indicates that at higher orbital speed of tool electrode during radial orbital EDM process more random patterns of re-solidified spheres, craters and cracks ware generated that resulted higher surface roughness.

\section{Effect on Overcut $\left(O_{c}\right)$}

Overcut was calculated after measuring the diameter of final cavities. The calculated overcut was plotted with orbital speed at different orbital radius and shown in Fig. 7. It was found that overcut was reducing with increasing in orbital speed of tool electrode. Significant reduction in overcut was observed at higher orbital speed with $1 \mathrm{~mm}$ and $1.5 \mathrm{~mm}$ orbital radius i.e. cavities created using $8 \mathrm{~mm}$ and $7 \mathrm{~mm}$ tool diameter.

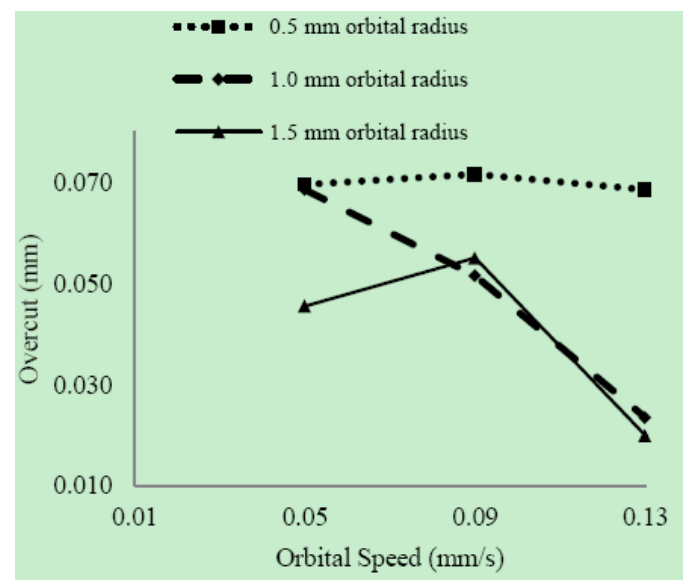

Fig. 7 Variation of overcut with orbital speed.

\section{CONCLUSIONS}

In this research work an attempt was made to perform the boring operation in electrical discharge machine. Adopting radial tool movement in EDM process, cavity diameters were bored to $10 \mathrm{~mm}$ diameter using three different diameters of tool electrodes namely, $7 \mathrm{~mm}, 8 \mathrm{~mm}$ and $9 \mathrm{~mm}$. These electrodes were given three different orbital radiuses namely, $1.5 \mathrm{~mm}, 1.0 \mathrm{~mm}$ and $0.5 \mathrm{~mm}$ at three different orbital speeds namely, $0.05 \mathrm{~mm} / \mathrm{s}, 0.09 \mathrm{~mm} / \mathrm{s}$ and $0.13 \mathrm{~mm} / \mathrm{s}$. The results indicate that MRR and average surface roughness of cavities increases with orbital speed irrespective of tool diameters (at all orbital radius) and overcut decreases with increase in orbital speed.

\section{REFERENCES}

[1] J. A. McGeough, Advance Methods of machining, Springer publication, 1988.

[2] V. K. Jain, Advanced Machining Processes, New Delhi: Allied Publishers Pvt. Ltd, 2009.

[3] E. Henriques, P. Pecas, and P. F. Chunha, "Perspective of mould making industry for digital global manufacturing," Digital Enterprise Technology, pp. 449-456, 2007.

[4] G. Karthikeyan, J. Ramkumar, S. Dhamodaran, and S. Aravindan, "Micro electric discharge milling process performance: An experimental investigation," International Journal of Machine Tools and Manufacture, vol. 50, pp. 718-727, 2010.

[5] K. Y. Song, D. K. Chung, M. S. Park and C. N. Chu, "EDM turning using a strip electrode," Journal of Material Processing Technology, vol. 213, pp. 1495-1500, 2013.

[6] E. S. Lee and S. O. Ahn, "Precision surface grinding of Mn-Zn ferrite with in-process electro-discharge dressing (IEDD)," International Journal of Machine Tools and Manufacture, vol. 39, pp. 1655-1671, 1999.

[7] K. V. Rao, B. S. N. Murthy, and N. M. Mohan, "Cutting tool condition monitoring by analyzing surface roughness, work piece vibration and volume of metal removed for AISI 1040 steel in boring," Measurement, vol. 46, pp. 4075-4084, 2013.

[8] H. K. Dave, K. P. Desai and H. K. Raval, "A Taguchi approach-based study on effect of process parameters in electro discharge machining using orbital tool movement," International Journal of Machining and Machinability of Materials, vol. 13, pp. 52-66, 2013.

[9] El- Taweel and M. S. Hewidy, "Enhancing the performance of electrical-discharge machining via various planetary modes," 
International Journal of Machining and Machinability of Materials, vol. 5, pp. 308-320, 2009.

[10] E. Bamberg and H. Sumet, "Orbital electrode actuation to improve efficiency of drilling micro-holes by micro-EDM," Journal of Material Processing Technology, vol. 209, pp. 1826-1890, 2009.

Sudhanshu Kumar is a research scholar in the Department of Mechanica Engineering at S. V. National Institute of Technology, Surat, Gujarat, India $\mathrm{He}$ has completed post graduation in Mechanical engineering in 2012 from S. V. National Institute of Technology, Surat, Gujarat, India. At present he is pursuing the Ph.D. in mechanical engineering from S. V. National Institute of Technology, Surat, Gujarat, India. His area of research is in unconventional machining process. Mr. Kumar is a member of American Society of Research.
Harshit K. Dave is currently serving as an Assistant Professor at the Department of Mechanical Engineering, S. V. National Institute of Technology, Surat, Gujarat, India. He has over ten years of teaching experience. His research interests include unconventional machining processes, micro machining processes, computer aided manufacturing and measurement, modelling and optimisation of machining processes, etc.

Keyur P. Desai is currently serving as a Professor at the Department of Mechanical Engineering, S.V. National Institute of Technology, Surat, Gujarat, India. He has over twenty eight years of teaching and research experience. His research interests include unconventional machining processes, computer aided manufacturing, cryogenics and its application, etc. He has successfully handled several collaborative research projects funded by various government agencies. 